\title{
Status and strategies for the management of head and neck cancer during COVID-19 pandemic: Indian Scenario
}

Anand Gupta, MD ${ }^{1}$

${ }^{1}$ Government Medical College and Hospital (GMCH)

April 27, 2020

Gupta, Anand ${ }^{1, \#}$; Arora, Vipin ${ }^{2}$; Nair, Deepa ${ }^{3}$; Agrawal,Nishant ${ }^{4}$; Su, Yuxiong $^{5}$; Holsinger, Christopher F. ${ }^{6}$; Chan, Jason ${ }^{7, \#}$

1 Department of Dentistry (Oral and Maxillofacial Surgery), Government Medical College \& Hospital, Chandigarh, India.

${ }^{2}$ Department of ENT and Head Neck Surgery, University College of Medical Sciences and GTB Hospital, Delhi, India.

${ }^{3}$ Department Head and Neck Surgical Oncology, Tata Memorial Centre, HBNI University, Mumbai, India.

${ }^{4}$ Section of Otolaryngology-Head and Neck Surgery, University of Chicago Medicine, Chicago, IL, United States.

${ }^{5}$ Division of Oral and Maxillofacial Surgery, Faculty of Dentistry,

The University of Hong Kong, Hong Kong SAR.

${ }^{6}$ Division of Head and Neck Surgery, Stanford University, Palo Alto, CA, USA.

${ }^{7}$ Department of Otorhinolaryngology, Head and Neck Surgery, The Chinese University of Hong Kong, Hong Kong.

Keywords: Strategies for management; head and neck cancer; COVID-19; pandemic; Indian Scenario.

Disclosure: Nothing to disclose.

Funding: No funding received.

\section{Corresponding Authors:}

Anand Gupta

Assistant Professor

Department of Dentistry (Oral and Maxillofacial Surgery),

Government Medical College and Hospital (GMCH) 
Sector 32 B, Chandigarh, INDIA

Pin code- 160030

Telephone no. +91-9810720642

E mail- dranandkgmc2@gmail.com

Jason YK Chan

Assistant Professor

Department of Otorhinolaryngology, Head and Neck Surgery,

The Chinese University of Hong Kong, Hong Kong.

Pin code-

Telephone no. +85 -235053288

Email :jasonchan@ent.cuhk.edu.hk

\section{Introduction}

Coronavirus disease 2019 (COVID-19), caused by the severe acute respiratory syndrome coronavirus 2 (SARS-CoV-2), has been declared a pandemic since the $11^{\text {th }}$ of March 2020 by the World Health Organization (WHO). ${ }^{1,2}$ All over the world, 'lock down' or 'social distancing' has been found to be the most effective method to control this outbreak. Due to the high infectivity and alarming increase in the number of cases affected by this contagious disease, most hospitals have decreased or all-together stopped elective interventions in patients suffering from head and neck cancer (HNC). Ambulatory visits have been curtailed, wards and operating rooms are emptied for emergency services and ventilators have been commandeered for COVID-19 patients.

In India, over 200,000 cases of HNC occur each year where nearly 80,000 oral cancers are diagnosed every year. ${ }^{3}$ Overall, $57.5 \%$ of global HNCs occur in Asia, especially in Indian subcontinent and they account for $30 \%$ of all cancers in India. ${ }^{4}$ In India, 60 to $80 \%$ of patients present with advanced disease as compared to $40 \%$ in developed countries. ${ }^{5}$ Oral cancer is the most common HNC in men in India, mainly due to the consumption of smoked and smokeless tobacco. ${ }^{6}$ When patients with head neck cancer present at a stage where resection is feasible, they can expect a reasonable outcome after the surgery and appropriate adjuvant treatment. ${ }^{7}$ During the current pandemic, delaying surgery for even 1-2 months may lead to more extensive surgery or inoperability, when only supportive care can be provided. Being semi-emergent in nature, treatment for these patients is currently on hold or delayed in most centres across the country.

This study was conducted to assess the impact of COVID-19 pandemic and inability of the health system to treat HNC in a timely fashion and how surgeons are coping to this emergent situation. This article highlights the situation in Indian, a country burdened with one of the highest incidence of HNC.

\section{Materials and Methods}

In this COVID-19 pandemic, the stakeholders (at least an attending surgeon) of major academic health institutions in India who are responsible for head neck cancer (HNC) care were contacted by phone and other electronic means of correspondence. Anonymity of the institute and the individual surgeon was ensured and verbal consent obtained. They were asked about the present situation of HNC services arising out of COVID-19 pandemic at their hospitals. The information sought was framed in the form of questions like- status of outpatient and inpatient services, acceptance of new patients, type of cancer surgeries being performed, management of patients in the postoperative period, safety measures taken during surgeries, guidelines followed, treatment of COVID-19 patients in their respective hospitals and availability of personal 
protective equipments (PPE). Recent guidelines on the management of cancer patients during COVID-19 pandemic were searched on the website of important health care bodies of India. All responses from different stakeholders and guidelines were analysed to understand the present situation in India.

\section{Results}

A total of 16 major head and neck health care facilities were contacted across India including all regions (Table 1). The majority of the contacted stakeholders were working in government (public funded) institutions ( $75 \%$, $\mathrm{n}=12$ ) as they have the highest workload of patients in Indian set up, where treatment is practically free to the patient. Out of the 16 hospitals, $50 \%(\mathrm{n}=8)$ were dedicated cancer centres and other half were tertiary care institutions with head and neck cancer facilities. A dedicated cancer centre, catering to a large urban population has been closed indefinitely due to the spread of COVID 19 in a large number of healthcare professionals. The majority $(69 \%, \mathrm{n}=11)$ of the institutions have halted outpatient facilities and elective surgeries, only emergency admissions and surgeries were continued in these centres (Table 1). Only 5 (31\%) institutes were providing all types of HNC services, but with an increased volume of outpatients despite a decreased volume of operations due to safety precautions and limited availability of personal protective equipment (PPE).Four of these are dedicated cancer centres and were performing the full spectrum of surgical procedures. Most institutions are surveying patients by clinic visits or through telephone consultations. Few $(12.5 \%, \mathrm{n}=2)$ institutions have started telemedicine consultations with patients. As per the present government regulations, COVID-19 test is not allowed for patients with no history and symptoms. The majority $(69 \%, \mathrm{n}=11)$ of the institutes are following institutional guidelines, while others are either following state or other guidelines. Availability of (PPE) and N95 mask are limited (63\%, n=10) at most of the centres and they are using them judiciously. Current recommendations by the government of India, does not allow for pre operative COVID-19 testing, so decision making for surgery on the basis of COVID-19 status is difficult.

The Ministry of health and family welfare, an apex health care body of India has categorized all suspected/positive patients into three groups and are managed in the respective COVID hospitals- Dedicated COVID Care Centre (DCCC), dedicated COVID Health Centre (DCHC) and dedicated COVID Hospitals (DCH). Out of 16 institutions contacted, four have been designated as DCHC and two as DCH.

Currently, there are no guidelines for the management of HNC in India during COVID-19 pandemic. The Foundation for Head and Neck Oncology (FHNO), a multi-specialty national society in India has provided guidelines for the management of HNC patients. These guidelines are elaborative and cover all aspect of management of HNC cancer patients, from surgical to non surgical modalities. As this is a non government body, they have advised to keep abreast of advisories and guidelines from the government of India, as these will supersede their guidelines.

\section{Discussion}

Cancer is the second leading cause of death globally, accounting for an estimated 24.5 million incident cancer cases and 9.6 million deaths, or one in six deaths, in 2018. ${ }^{8}$ Head and neck cancer in India has a distinct demographic profile, risks factors, food habits, and personal and family history. HNC is a major public health problem in India, mainly due to the widespread use of tobacco. In contrast to the west, where it is the $6^{\text {th }}$ most common cancer, HNC in India is the commonest cancer of males in India. ${ }^{3}$ Already burdened with the high patient load and high percentage of late-stage HNC patients, the spread of COVID-19 has further deteriorated the situation.

As of April 14, 2020, corona virus disease 2019 (COVID-19) has affected 1,914,916 persons worldwide. The death toll in the highest affected countries like Italy is approaching 12000 people, with Spain not far behind. The USA has reported more than 164000 cases of the disease, including more than 38000 cases in New York City alone. ${ }^{9}$ India, a country of 1.35 billion people, has also come in the grasp of this highly contagious disease with its first case reported on 30 January in the state of Kerala. ${ }^{10}$ Now the footprint of COVID-19 has spread in almost all states, affecting more than 11000 people and with the death of more than 370 people as on $14^{\text {th }}$ April $2020 .^{9}$ 
Due to the rising number of COVID-19 patients in India, almost all government hospitals and teaching health care institutions are on high alert and doctors are the main task force for managing this pandemic. After the announcement of 21 days lock down throughout the whole India on the 24th march 2020 midnight by the Indian government, all elective surgeries and outpatient services at majority of hospitals were withheld to control this menace and vacating the facilities in stage wise manner to harness the resources. Only emergency services were continued for the management of life threatening problems. ${ }^{11}$ Most of the major government hospitals were aligned to assess their resources and convey the present status of the availability of ICU beds, ventilators and beds availability. Gradually, beds in the wards were vacated by discharging stable patients and only critical patients were kept in hospitals. Beds of each department catering emergency patients were asked to join hands and combine their beds in a limited area on a sharing basis so that other areas can be made available as isolation wards with sufficient number of beds for the growing number of COVID-19 patients.

Recently to contain the spread of disease, the Indian government has earmarked selected facilities which will be dedicated for COVID-19 management. They have proposed three types of COVID dedicated facilities as COVID care centre (CCC), Dedicated COVID Health Centre (DCHC) and Dedicated COVID Hospitals (DCH). All these facilities will have separate ear marked areas for suspected and confirmed cases. Suspected and confirmed cases will not be allowed to mix under any circumstances. Out of these both DCHC and DCH would be the existing hospitals and most of them are secondary to tertiary care government hospitals. ${ }^{12}$ HNC surgeries together with other cancer surgeries are majorly affected after major health care institutions were converted into dedicated COVID-19 centres. Meanwhile, few dedicated cancer centres are able to continue doing HNC surgeries but in limited numbers by following their own institutional guidelines. But this situation is dynamic and an expected exponential increase in the number of COVID-19 patients and probable community spread may lead to overburdened health care facilities and more stringent policies to take up new cases.

India, which has a high burden of head and neck cancer, is compounded with long waiting lists in all hospitals of India. A problem that is particularly worse in government funded hospitals, which cater to the poorest of society. With further delays in surgery during the pandemic of COVID-19, the burden will exponentially increase. The biggest problem will be to manage such a high load of these malignancies after the situation is normalized. The patients may become inoperable and deemed only for palliative treatment. The Government of India is taking a lot of measures to contain this disease and purchasing a large number of ventilators to cater the expected increase of COVID-19 patients in the near future. But we also need guidelines and a mechanism to surgically treat at least those head and neck cancer patients which are in dire need of surgery for a reasonable survival.

The practice in other countries where the infection is more severe than in India has been to create new and innovative care pathways. In the United Kingdom, NHS England has rapidly supported the creation of 'cancer hubs', where cancer patients from multiple tumour groups are fast tracked on priority basis. To ensure full stakeholder participation, the hubs have suspended conventional regulatory requirements to referring surgical teams to operate at the hub. The hub is maintained as COVID-19 free by requiring patients to self-isolate when they have been accepted for intervention and regular testing for COVID-19 in the pre-treatment period. Patients needing urgent cancer surgeries are referred to such dedicated centres and are scheduled for treatment as decided by the tumour board. Their tumour boards conduct virtual multidisciplinary team (MDT) meetings and decisions are taken accordingly. ${ }^{13}$ The American College of Surgeons (ACS) has given guidelines for triage of cancer surgeries during this pandemic and recommended the decision to be taken by the MDT team based on the available resources and situation pertaining in their region. ${ }^{14}$

During the current pandemic, the important points to consider are that all head and neck procedures including simple clinical examinations are potentially aerosol generating and should be considered high risk. Testing of COVID-19 is limited and cannot be performed in all patients. Protective supplies, such as N95 masks, PPE gowns, gloves and other protective materials are in short supply or unavailable in many 
institutions. As the illness progresses our systems may be burdened with potential shortage of beds and health care manpower. Also there will be difficulty and uncertainty in mobility of patients due to lockdowns and quarantine. Availability of blood and blood products may become a challenge. ICU Bed/ ventilators may be at a premium and scarce. Cancer patients are likely to be more vulnerable in India during COVID19 , so decisions to treat the patient should be taken on the basis of risk benefit ratio during this epidemic period.

At present there are no national guidelines for cancer patients from the government of India, so we have to either depend on institutional, state or association guidelines. The foundation for head and neck oncology (FHNO) has given guidelines which covers diagnosis, treatment and follow up of HNC patients and is described in Table $3 .^{15}$

\section{Conclusions}

Head and neck cancer is an important public health problem in India. The current COVID-19 pandemic has presented an unprecedented situation in human history, with massive disruption of health care activities. In India, the treatment of HNC patients has been severely disrupted, with increased waiting times, patient anxiety and potentially worse patient outcomes. With the disruption likely to continue for the foreseeable future, we believe that lockdown measures may be appropriately amended to suit local needs. Patients need to be directed to alternative treatment facilities, separate from a COVID-19 facility. Pre-operative screening for COVID-19, availability of PPE and isolation of suspected patients will act as confidence builders for healthcare teams treating cancer patients during these challenging times. In the absence of clear views on the future trends of this pandemic, all measures must be taken to prevent patients with non-COVID diseases coming to harm.

\section{References}

1. del Rio C, Malani PN. COVID-19-New Insights on a Rapidly Changing Epidemic. JAMA . 2020. doi:10.1001/jama.2020.3072

2. WHO (World Health Organization). Statement on the meeting of the International Health Regulations (2005) Emergency Committee regarding the outbreak of novel coronavirus (2019-nCoV). WHO Newsletter . 2020 .

3. Kulkarni MR. Head and Neck Cancer Burden in India. Int J Head Neck Surg . 4(1):29-35. doi:10.5005/jpjournals-10001-1132

4. P C. Head and Neck Surgery. J Can Res Ther . 2009;5:143. doi:10.1177/0194599811415818a38

5. Coelho KR. Challenges of the Oral Cancer Burden in India. J Cancer Epidemiol . 2012;2012:17. doi:10.1155/2012/701932

6. Niaz K, Maqbool F, Khan F, Bahadar H, Ismail Hassan F, Abdollahi M. Smokeless tobacco (paan and gutkha) consumption, prevalence, and contribution to oral cancer. Epidemiol Health . 2017;39:e2017009. doi:10.4178/epih.e2017009

7. Hamoir M, Holvoet E, Ambroise J, Lengelé B, Schmitz S. Salvage surgery in recurrent head and neck squamous cell carcinoma: Oncologic outcome and predictors of disease free survival. Oral Oncol . 2017;67:1-9. doi:10.1016/j.oraloncology.2017.01.008

8. Latest global cancer data: Cancer burden rises to 18.1 million new cases and 9.6 million cancer deaths in 2018. https://www.who.int/cancer/PRGlobocanFinal.pdf. Accessed April 16, 2020.

9. Coronavirus disease 2019 (COVID-19) Situation Report - 85. https://www.who.int/docs/default-source/coronaviruse/situa reports/20200415-sitrep-86-covid-19.pdf?sfvrsn=c615ea20_2. Accessed April 16, 2020.

10. India's first coronavirus case: Kerala student in Wuhan tested positive | Business Standard News. 
https://www.business-standard.com/article/current-affairs/india-s-first-coronavirus-case-kerala-student-in-wuhantested-positive-120013001782_1.html. Accessed April 16, 2020.

11. AIIMS to shut down OPD from March 24 till further notice - The Economic Times. https://economictimes.indiatimes.com/ to-shut-down-opd-from-march-24-till-further-notice/articleshow/74772664.cms?from=mdr. Accessed April 16, 2020 .

12. Guidance document on appropriate management of suspect/confirmed cases of COVID-19. https://www.mohfw.gov.in/pdf Accessed April 16, 2020.

13. NHS England and NHS Improvement London i. Cancer Services In London During the Covid-19 Pandemic. https://www.england.nhs.uk/london/2020/03/27/cancer-services-in-london-during-the-covid-19pandemic/. Accessed April 16, 2020.

14. COVID-19 Guidelines for Triage of Cancer Surgery Patients. https://www.facs.org/covid-19/clinicalguidance/elective-case/cancer-surgery. Accessed April 16, 2020.

15. FOUNDATION for HEAD and NECK ONCOLOGY. http://www.fhno.org/pdf/Guidelines_Covid-19_FHNO.pdf. Published 2020. Accessed April 16, 2020.

Table 1: Geographical distribution of head and neck cancer facilities from which the information was collected.

\begin{tabular}{llll}
\hline Region & State / Union territory & Tertiary care hospitals & Dedicated Cancer centres \\
\hline North & Delhi & 4 & 4 \\
& Punjab/ Chandigarh & 2 & - \\
South & Karnataka & - & 1 \\
& Kerala & 1 & - \\
\multirow{3}{*}{ West } & Pondicherry & 1 & - \\
& Gujarat & - & 1 \\
& Maharashtra & - & 1 \\
& West Bengal & - & 1 \\
& Total & $\mathbf{8}$ & $\mathbf{8}$ \\
\hline
\end{tabular}

Table 2: Responses from the institutes with head and neck oncology services.

\begin{tabular}{lllll}
\hline $\begin{array}{l}\text { Information } \\
\text { sought }\end{array}$ & Responses & $\begin{array}{l}\text { Tertiary care } \\
\text { hospitals with } \\
\text { Oncology services } \\
(\mathbf{n}-8)\end{array}$ & $\begin{array}{l}\text { Dedicated } \\
\text { Cancer centres } \\
(\mathbf{n}-8)\end{array}$ & Total (n-16) \\
$\begin{array}{l}\text { Outpatient } \\
\text { department working }\end{array}$ & Yes No & 44 & 511 \\
$\begin{array}{l}\text { Inpatient facilities } \\
\text { working }\end{array}$ & $\begin{array}{l}\text { All types (limited) } \\
\text { Emergency only }\end{array}$ & 17 & 44 & 511 \\
$\begin{array}{l}\text { Accepting new } \\
\text { patients? }\end{array}$ & Yes No & 17 & 44 & 511 \\
$\begin{array}{l}\text { Type of surgeries } \\
\text { being performed }\end{array}$ & $\begin{array}{l}\text { All types (limited) } \\
\text { Emergency only }\end{array}$ & 17 & 44 & 511 \\
$\begin{array}{l}\text { Safety precautions } \\
\text { Guing surgery }\end{array}$ & PPE/N95 Standard & 53 & 62 & 115 \\
& $\begin{array}{l}\text { Institutional State } \\
\text { other guidelines }\end{array}$ & 621 & 511 & 1132
\end{tabular}




\begin{tabular}{|c|c|c|c|c|}
\hline $\begin{array}{l}\text { Management of } \\
\text { immediate post } \\
\text { operative cases }\end{array}$ & $\begin{array}{l}\text { Patient +telephone } \\
\text { Telephone only } \\
\text { Telemedicine }\end{array}$ & 161 & 431 & 592 \\
\hline COVID-19 centre & $\mathrm{DCHC}^{*} \mathrm{DCH} * \mathrm{No}$ & 422 & 008 & 4210 \\
\hline $\begin{array}{l}\text { Availability of } \\
\text { personal protective } \\
\text { equipment }\end{array}$ & $\begin{array}{l}\text { Available Limited } \\
\text { Not available }\end{array}$ & 260 & 341 & 5101 \\
\hline
\end{tabular}

* DCHC: Dedicated COVID Health Centre and

DCH : Dedicated COVID Hospitals

Table 3: Brief of guidelines and recommendations given by FHNO for the management of HNC during COVIS-19 epidemic. ${ }^{15}$

\section{DIAGNOSIS}

Fibreoptic and direct laryngoscopies should be avoided unless absolutely mandatory, to help protect healthcare workers fror TREATMENT

Surgery It should be taken in consideration with its likely outcomes, likelihood of curing the cancer, safety considerations a FOLLOW UP

It is advised to minimise all follow up appointments. Defer follow up for patients with low risk of recurrence (e.g. 18-24 mo 